\title{
DAMPAK KINERJA BAURAN PEMASARAN TERHADAP KEPUTUSAN KULIAH CALON MAHASISWA POLITEKNIK X CIMAHI
}

\author{
THE EFFECTS OF MARKETING MIX TO STUDY DECISION \\ OF STUDENT CANDIDATES OF POLYTECHNIC X CIMAHI
}

\author{
Suharyanto \\ Prodi Teknik Industri Universitas Kebangsaan \\ Yanto_sy2008@yahoo.com
}

\begin{abstract}
The higher education service providing become one of business which needs hard working especially in student recruitment. The alumni of vocational high school (SMK) and general high school (SMA) who will to continue study in higher education, can become to be opportunities. To keep these, the higher education institutions have to compete with the others, applying right marketing mix. This research article shows the marketing mix performance effects to student candidates decision to study in Polytechnic X Cimahi. The research population are student canditates in academic year of 2017, and 50 samples were got simple randomly. The effects of marketing communication mix and marketing mix to student decision analysed using simple linier regression model. The research result shows that variables of marketing mix performance gives medium effects $61,4 \%$ to student decision, and $38,6 \%$ effected by others. The linier regression model constructed is $Y=0,690 \mathrm{X}+1,248$.
\end{abstract}

Keywords: marketing mix, study decision, linier regression

\begin{abstract}
Abstrak
Jasa penyelenggaraan pendidikan tinggi saat ini menjadi kegiatan yang menuntut usaha keras dalam meraih mahasiswa baru. Banyaknya lulusan sekolah menengah tingkat atas (SMA/SMK) yang berniat melanjutkan studi menjadi peluang yang baik. Untuk menangkap peluang tersebut, institusi perguruan tinggi harus bersaing ketat dengan perguruan tinggi lain, dengan menerapkan bauran pemasaran yang tepat. Artikel ini merupakan hasil penelitian tentang kinerja bauran pemasaran serta dampaknya terhadap keputusan kuliah calon mahasiswa Politeknik X Cimahi. Populasi dalam penelitian ini adalah calon mahasiswa pendaftar tahun 2017. Sampel diambil secara acak sederhana sebanyak 50 calon. Analisis hubungan variabel kinerja bauran pemasaran terhadap keputusan kuliah menggunakan regresi linier sederhana. Hasil penelitian menunjukkan bahwa variabel bauran pemasaran memberikan dampak cukup signifikan 61,4\% terhadap keputusan kuliah, dan 38,6\% dipengaruhi oleh faktor lain. Model regresi yang terbentuk adalah $\mathrm{Y}=0,690 \mathrm{X}+1,248$.
\end{abstract}

Kata kunci: bauran pemasaran, keputusan kuliah, regresi linier 


\section{PENDAHULUAN}

\section{Latar Belakang}

Perkembangan usaha jasa pada masa sekarang ini berkembang pesat seiring dengan perkembangan jumlah penduduk, pertumbuhan kebutuhan hidup maupun perkembangan pendapatan dan daya beli masyarakat. Begitu juga jasa pendidikan tinggi berkembang seiring dengan perkembangan kebutuhan akan pendidikan. Masyarakat akan memilih dan menentukan perguruan tinggi tertentu sesuai dengan beberapa alasan, misalnya dilihat dari kualitas, biaya pendidikan, jarak dari tempat tinggal, reputasi dan sebagainya. Di sisi lain ada hal lain yang dapat mempengaruhi pilihan seorang calon mahasiswa, yaitu terkait dengan informasi yang diperolehnya tentang perguruan tinggi yang akan didaftari atau dipilihnya. Faktor informasi yang diperoleh dan komunikasi ini bisa cukup berarti memberikan pengaruh calon mahasiswa.

Pihak penyelenggara perguruan tinggi berkepentingan untuk menyampaikan informasi perguruan tingginya melalui proses komunikasi yang biasa dikenal dengan promosi. Usaha kegiatan promosi ini menjadi salah satu kegiatan yang menuntut usaha keras dalam meraih mahasiswa baru. Banyaknya lulusan sekolah menengah atas (SMA/SMK) yang berniat melanjutkan studi menjadi peluang yang dapat dimanfaatkan untuk bisa menjadi mahasiswa baru. Disisi lain banyaknya perguruan tinggi lain bisa menjadi pesaing yang akan mempersulit perolehan mahasiswa baru dan peluang yang ada akan terlewatkan. Untuk menangkap peluang tersebut, suatu perguruan tinggi harus bersaing ketat dengam perguruan tinggi lain. Salah satunya dengan menerapkan bauran promosi dan bauran pernasaran yang baik. Aktivitas komunikasi pemasaran politeknik X Cimahí telah dilakukan seperti pada tabel 1 berikut.

Tabel 1. Jenis dan Frekuensi Media Promosi Politeknik X Cimahi

\begin{tabular}{ll}
\hline Media promosi & Frekuensi \\
- brosur & Per tahun \\
\hline
\end{tabular}

\begin{tabular}{ll}
\hline - koran & 12 \\
\hline - referensi sdr/teman & Tak terbatas \\
\hline - promosi ke sekolah & 50 sekolah \\
\hline - spanduk & 25 buah \\
\hline - radio & 1 bulan \\
\hline *)sumber: Tim penerimaan mahasiswa 2017
\end{tabular}

Politeknik X Cimahi adalah salah satu perguruan tinggi vokasi yang berada di kota Cimahi, berdiri pada tahun awal tahun 2002. Kemudian berkembang dengan memiliki sembilan program studi (teknik mesin, teknik sipil, teknik elektro, teknik alat berat, ilmu komputer, mekatronika, rekam medis, analisis kimia, akuntansi). Pada awal berdiri jumlah mahasiswanya masih sedikit, kemudian berkembang pada tahun 2017 mencapai 1400an, dengan pendaftar mahasiswa baru 400 lebih. Berbagai upaya dengan menerapkan konsep bauran pemasaran sudah dilakukan oleh Politeknik X Cimahi, namun pencapaian jumlah mahasiswa/tersebut dirasakan sangat berat dalam køndisi persaingar ketat antar perguruan tinggi swasta saat jiin, karena terus bermunculannya perguruan tinggi lain, dengan berbagai fasilitas, biaya ber ariasi, dosen, sarana dan prasarana kuliah yang bagus dan daya tarik promosi lainnya, jumlah pendaftar di Politeknik X Cimahi cenderung mengalami penurunan. Dalam kondisi seperti ini pihak manajemen, sebagai antisipasi terhadap persaingan yang ketat dalam meraih calon mahasiswa baru, menjalankan berbagai macam bentuk program terkait dengan bauran pemasaran.

\section{Rumusan dan Manfaat Penelitian}

Pihak Politeknik X Cimahi berharap dan menduga bauran pemasaran berpengaruh terhadap keputusan pilihan kuliah calon mahasiswa. Rumusan masalah penelitian ini adalah sebagai berikut:

1.Bagaimana kinerja bauran pemasaran Politeknik X Cimahi?

2.Bagaimana keputusan calon mahasiswa untuk kuliah di Politeknik X Cimahi?

3. Bagaimana pengaruh kinerja bauran pemasaran terhadap keputusan kuliah calon mahasiswa Politeknik X Cimahi? 
Dengan diketahuinya kinerja bauran pemasaran serta pengaruhnya terhadap keputusan kuliah akan bermanfaat dalam pengembangan strategi pemasaran, khususnya aspek komunikasi kepada calon mahasiswa Politeknik X Cimahi; sebagai masukan dalam penentuan konten promosi maupun bauran pemasaran dan sebagai bahan informasi untuk perbaikan internal Politeknik $\mathrm{X}$ Cimahi.

\section{Kajian Teori}

Dalam model makro proses komunikasi, terdapat dua bagian penting yaitu pengirim dan penerima. Terdapat dua alat penting yaitu pesan (message) dan media, serta terdapat empat elemen fungsi yaitu encoding, decoding, response dan feedback, juga terdapat noise (pesan lain yang dapat mempengaruhi komunikasi) dalam sistem (Duncan dan Sandra dalam Schiffman\& Kanuk, 2006). Komunikasi adalah pengiriman pesan dari pengirim kepada penerima melaui medium (saluran) pengiriman. Lima hal penting yang harus diperhatikan, yaitu pengirim (sender), pesan (message), media (medium), penerima (receiver) (Schiffman\& Kanuk, 2006). Model komunikasi dasar ini bisa dilihat pada gambar 1 berikut.

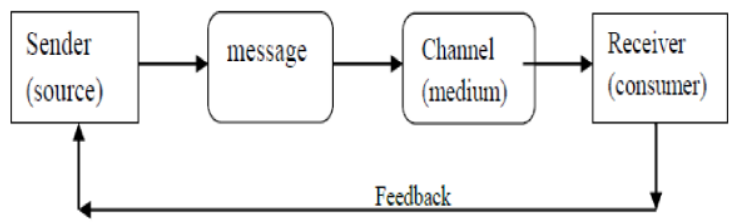

Gambar 1. Model Komunikasi Dasar Sumber: Schiffman \& Kanuk (2006)

Bowersox dan Moorash dalam Fill dan Jameson (2014), menunjukkan bagainana arus pemasaran, termasuk arus informasi, dapat digambarkan sebagai jaringan yang menjual suatu tujuan berupa kepuasan konsumen atas kebutuhan dan keinginan. Pada tingkat clasar, komunikasi dapat menginformasikan dan membuat konsumen perhatian terhadap apa yang ditawarkan organisasi, komunikasi bisa mendorong ketertarikan konsumen, hubungan pertukaran, komunikasi dapat digunakan untuk memperkuat pengalaman dan komunikasi pemasaran bisa bertindak sebagai pembeda (differentiator) khususnya dalam pasar yang terdapat sedikit persaingan produk dan merk. Tahapan respon pelanggan terdiri atas beberapa tahap berupa kognitif, afektif, dan perilaku (model hirarki-respon). Dalam model AIDA, tahap komunikasi-respon terdiri dari empat tahapan: (Schiffman \& Kanuk, 2006)

- perhatian (attention), respon penerima pesan terhadap informasi yang diterima hanya sebagai pengetahuan dan perhatian saja

- ketertarikan (interest), respon penerima pesan terhadap informasi yang diterimanya akan menyebabkan timbulnya rasa tertarik akan produk yang ditawarkan

- keinginan (desire), respon penerima pesan terhadap informasi yang diterima menyebabkan keinginan kuat untuk membeli

- tindakan (action), respon penerima pesan terhadap informasi yang diterimanya menyebabkan tindakan membeli produk

Definisi dalam Dictionary of Marketing, AMA, untuk dapat memasarkan produknya kepada pelanggan, produsen barang atau jasa perlu merumuskan bauran komunikasi pemasaran (marketing communication mix), yang terdiri dari delapan bentuk (Kotler, 2009:512):

1. Periklanan (Advertising), merupakan bentukbentuk berbayar dari presentasi non-personal dan promosi ide-ide, barang atau jasa oleh sponsor yang teridentifikasi.

2. Promosi penjualan (Sales promotion), merupakan variasi bentuk insentif jangka pendek yntuk mendukung uji coba atas pembeiran barang ataujasa.

3. Kegiatan dan pengalainan (Events and experience), berupa berbagai kegiatan yang disponsori perusahaan dan program yang didisain khusus untuk menciptakan interaksi yang berhubungan dengan brand.

4. Publisitas dan hubungan masyarakat (Public relation and publicity), merupakan bentukbentuk program yang didesain untuk mempromosikan atau melindungi image perusahaan atau produk-produknya.

5. Pemasaran langsung (Direct marketing), menggunakan surat, telepon, faximili, e-mail atau internet untuk mengkomunikasikan secara langsung, mengumpulkan tanggapan langsung dari pelangan atau calon pelanggan.

6. Pemasaran interaktif (Interactive marketing), merupakan aktivitas langsung secara on-line dan program yang didesain untuk mengikutsertakan pelanggan/calon pelanggan secara langsung/tidak langsung untuk meningkatkan kesadaran, memperbaiki image atau penjualan barang atau jasa.

7. Pemasaran dari mulut ke mulut (Word-ofmouth marketing), merupakan bentuk orang ke orang secara oral, tertulis atau komunikasi 
elektronik yang berhubungan dengan penilaian atau pengalaman atas pembelian/penggunaan produk barang/jasa.

8. Penjualan pribadi (Personal selling), interaksi tatap muka dengan calon pembeli untuk tujuan membuat paparan, menjawab pertanyaan dan mencari order pembelian.

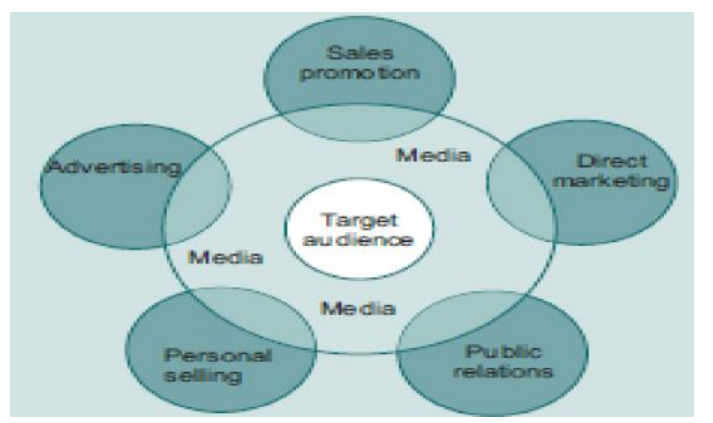

Gambar 2. Tools dan posisi bauran komunikasi pemasaran

*) Sumber: Fill dan Jamieson (2014)

Pengertian jasa menurut Lovelock, (2004) yaitu: Aktivitas ekonomi yang menghasilkan nilai dan memberikan manfaat (benefit) kepada pelanggan pada waktu dan tempat tertentu melalui perubahan yang diinginkan, menjadi bagian dari, oleh penerima jasa tersebut. Jasa adalah semua aktivitas ekonomi dimana hasilnya bukan produk atau benda fisik, yang pada umumnya dikonsumsi bersamaan dengan saat diproduksi, dan memberikan nilai tambah (seperti keutamaan, waktu cepat, kenyananan atau kesehatan) yang secara esensial tidak terlihat oleh pembeli (Zeithaml, 2006). Karakteristik produk jasa bersifat iniangible (tidak terlihat), heterogen, simultan antara produksi dan konsumsi serta bersifat perishable. Jasa tidak dapat disimpan dan fluktuasi demand sulit dikelola. Produksi dan konsumsi simultan, produksi masal jasa sulit dilakukan. Heterogenitas (keberagaman), jasa beragam tergantung waktu, Organisasi dan orang seiring dengan kualitas yang diperlukan oleh pelanggan. Kualitas jasa dan kepuasan pelanggan sangat tergantung pada apa yang terjadi secara nyata saat itu (real time), termasuk aktivitas tenaga kerja dan interaksi tenaga kerja dengan pelanggan. Perishabilitas, sifat jasa yang tidak dapat dihemat, disimpan, dijual kembali atau dikembalikan, peramalan demand jasa, penggunaan kapasitas secara kreatif menjadi penting dan menantang (Zeithaml, 2006).

Proses utama dari pemasaran adalah menyampaikan standar kehidupan yang lebih baik melalui komunikasi (Kotler, 2003). Dengan pemahaman terhadap konsumen, kebutuhan dan kita dapat menentukan program komunikasi, pesan yang dapat mempengaruhi dan menjangkau konsumen dan keinginan mereka, (Yeshin dalam Baker (2003). Konsep bauran pemasaran (marketing mix) adalah perangkat alat pemasaran yang digunakan perusahaan untuk mengejar tujuan pemasarannya (Borden dalam Kotler, 2007). Alat-alat ini dikelompokkan menjadi empat $\mathrm{P}$, terdiri dari produk (product), harga (price), tempat (place) dan promosi (promotion) (McCarthy dalam Kotler, 2007). Pengembangan empat $\mathrm{P}$ dalam pemasaran jasa menjadi tujuh $\mathrm{P}$ (product, price, place, promotion, people, physical eviderce and process) dilakukan oleh Booms dan Bitner (Zeithaml, 2006).

\section{METODE PEIEL TTIAN}

\section{Kerangka Pernikiran}

Pendidikan tinggi adalah jenjang pendidikan setelah pendidikan menengah yang mencakup program diploma, program sarjana, program magister, program doktor, dan program profesi, serta program spesialis, yang diselenggarakan oleh perguruan tinggi berdasarkan kebudayaan bangsa Indonesia (UU RI Nomor 12 tahun 2012). Politeknik X Cimahi, bergerak dalam jasa pendidikan, dengan produk yang dijual adalah berupa layanan program pendidikan jenjang diploma (D-III dan D-IV). Entitas produk jasa pendidikan politeknik X Cimahi terdiri dari:

- Produk, berupa program pendidikan tinggi jenjang ahli madya (D-III) dan sarjana terapan (D-IV) bidang ilmu-ilmu teknik, kesehatan dan akuntansi dengan lama studi 3 (6 semester) dan 4 tahun (8 semester).

- Harga, biaya-biaya yang harus dibayarkan oleh mahasiswa selama mengikuti kuliah di Politeknik X Cimahi, berupa biaya pendidikan (biaya pengembangan pendidikan, biaya kuliah/spp dan sks per semester, biaya praktek laboratorium, praktek lapangan, tugas akhir, kemahasiswaan, biaya ujian (UTS/UAS), biaya sidang akhir dan wisuda.

- Tempat, adalah tempat berlangsungnya proses belajar, berupa teori di kelas maupun praktek laboratorium dan praktek kerja lapangan di industri/perusahaan.

- Promosi, berhubungan dengan kegiatan mengkomunikasikan produk politeknik X Cimahi kepada calon mahasiswa, dengan 
menerapkan bauran komunikasi pemasaran dan menggunakan berbagai media promosi.

- Proses, berhubungan dengan pelaksanaan atau proses berlangsungnya kegiatan belajarmengajar baik teori maupun praktek.

- Orang, terdiri dari staf pengajar (dosen, asisten dosen), laboran, pembimbing praktek/tugas akhir, dosen wali, pustakawan, petugas administrasi dan seluruh orang yang terlibat dalam penyelenggaraan proses belajar

- Bukti fisik, merupakan benda-benda fisik yang berhubungan dengan tempat berlangsungnya proses, berupa sarana/prasarana belajar, misalnya: ruang belajar teori, laboratorium, asrama mahasiswa, peralatan praktek dan fasilitas lainnya.

Proses komunikasi perlu dilakukan secara efektif oleh manajemen,agar calon mahasiswa dapat dipengaruhi dan memilih kuliah di Politeknik X Cimahi. Untuk itu variabel penelitian terdiri dari:

-variabel bebas (independent variable) yang diterapkan adalah bauran pemasaran (7) $\mathrm{P})$.

-variabel terikat (dependent variable) berupa keputusan kuliah di Politeknik X Cimahi.

Kerangka pemikiran ini dapat digambarkan dalam gambar 1 sebagai berikut:

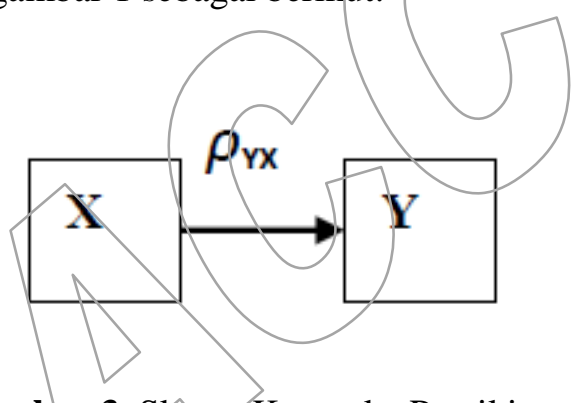

Gambar 3. Skèma Kerangka Pemikiran

Keterangan

$\mathrm{X}$ : variabel bebas, berupa bauran pemasaran dari Politeknik X Cimahi.

Y: variabel terikat, yaitu keputusan calon mahasiswa untuk kuliah di Politeknik X Cimahi.

$\boldsymbol{\rho}_{\mathbf{y x}}$ : pengaruh bauran pemasaran terhadap keputusan kuliah calon mahasiswa Politeknik X.

\section{Hipotesis}

Hipotesis ini berhubungan dengan pengaruh bauran pemasaran terhadap keputusan kuliah di Politeknik X Cimahi:
Ho : tidak ada pengaruh bauran pemasaran terhadap keputusan kuliah di Politeknik X Cimahi.

H1: ada pengaruh bauran pemasaran terhadap keputusan kuliah di Politeknik X Cimahi.

\section{Populasi dan Sampel}

Penelitian ini mengambil obyek pada bauran pemasaran serta pengaruhnya terhadap pilihan kuliah calon mahasiswa dengan lokasi kampus Politeknik X di Kota Cinnahi. Data diperoleh secara langsung dari responden calon mahasiswa (berupa kuesioner) dan dari pihak manajemen serta daí sumber lain berupa wawancara dan pengamatan. Penelitian ini bersifat deskriptif verifikatîf, hubungan variabel bebas dan variabel terikat dianalisis meriggunakan model regresi linier sederhana (simple linier regression). Populasi penelitian ini adalah seluruh calon mahasiswa yang mendaftar di Politeknik X Cimahi tahun 2017 sebanyak 435 calon dan sampel diambil sebanyak 50 calon secara acak sederhana (simple random sampling). Setiap variabel diuraikan atas beberapa subvariabel dengan alternatif jawaban yang dibuat dalam skala Likert dengan 5 (lima) alternatif jawaban. Nilai bobot jawaban dapat dilihat dalam tabel 4 . berikut:

Tabel 4. Nilai skala instrument

\begin{tabular}{lc}
\hline \multicolumn{1}{c}{ Pernyataan positif } & Nilai \\
\hline Sangat baik & 5 \\
\hline Baik & 4 \\
\hline Cukup & 3 \\
\hline Tidak baik & 2 \\
\hline Sangat tidak baik & 1 \\
\hline
\end{tabular}

\section{Operasionalisasi Variabel}

Variabel penelitian diuraikan menjadi 22 pertanyaan. Untuk variabel $\mathrm{X}$ (bauran pemasaran) terdiri dari produk, harga, distribusi, orang, proses dan promosi dan bukti. Sedangkan variabel keputusan kuliah (Y) digunakan model AIDA (attention, interest, desire, action), Skala ukur instrumen penelitian menggunakan skala ordinal berupa skala Likert. 
Operasionalisasi variabel dan alur penelitian terlihat dalam tabel 5 dan gambar 4 berikut.

Tabel 5. Operasionalisasi variabel penelitian

\begin{tabular}{|c|c|c|c|}
\hline $\begin{array}{l}\text { Variabel/ } \\
\text { subvariabel }\end{array}$ & Definisi & Indikator & Satuan ukuran \\
\hline $\begin{array}{l}\text { Bauran } \\
\text { Pemasaran }\end{array}$ & \multicolumn{3}{|c|}{$\begin{array}{l}\text { Kumpulan adalah perangkat alat pemasaran yang digunakan perusahaan untuk } \\
\text { mengejar tujuan pemasarannya }\end{array}$} \\
\hline \multirow{18}{*}{$\begin{array}{l}\text { Bauran } \\
\text { pemasaran }\end{array}$} & Produk & Kualitas program kuliah & Tingkat kualitas \\
\hline & & Daya tarik keterampilan/keahlian & Tingkat daya tari \\
\hline & & Kemudahan memperoleh pekerjaan & Tingkat kemudahan \\
\hline & & Daya tarik pemilik yayasan & \\
\hline & Harga & Keterjangkauan harga & Tingkat-keterjangkauan \\
\hline & Distribusi & Kestrategisan lokasi kampus & Tingkat kestrategisan \\
\hline & Orang & Kualitas dosen dan admin & Tingkat kualitas \\
\hline & Proses & Kemudahan proses kuliah & Tingkat kemudahan \\
\hline & Bukti fisik & Kondisi fisik gedung kuliah & Tingkat kondisi fisik \\
\hline & & Kelengkapan fasilitas lab. & Tingkat kelengkapan \\
\hline & & Variasi lokasi lahan PKL & Tingkat variasi \\
\hline & Promosi & Daya tarik spanduk/baliho & Tingkat daya tarik \\
\hline & & Kejelasan iklan media cetak/koran & Tingkat kejelasan \\
\hline & & Daya tarik iklan media elektronik & Tingkat daya tarik \\
\hline & $\nabla$ & Kelengkapan informasi dlm brosur & $\begin{array}{l}\text { Tingkat kelengkapan } \\
\text { informasi }\end{array}$ \\
\hline & & Daya tarik presentasi/seminar & Tingkat daya tarik \\
\hline & & Daya tarik pameran & Tingkat daya tarik \\
\hline & & Referensi teman/ saudara/ dsb. & Tingkat pengaruh \\
\hline \multirow[t]{2}{*}{$\begin{array}{l}\text { Keputusan } \\
\text { kuliah (Y) }\end{array}$} & $\begin{array}{l}\text { Hirarki } \\
\text { tanggapan } \\
\text { pelanggan }\end{array}$ & Attention (perhatian) & Tingkat perhatian \\
\hline & & Interest (tertarik) & Tingkat ketertarikan \\
\hline
\end{tabular}




\begin{tabular}{|l|l|l|}
\hline & Desire (keinginan) & Tingkat keinginan \\
\cline { 3 - 3 } & Action (tindakan) & Tingkat keputusan kuliah \\
\hline
\end{tabular}
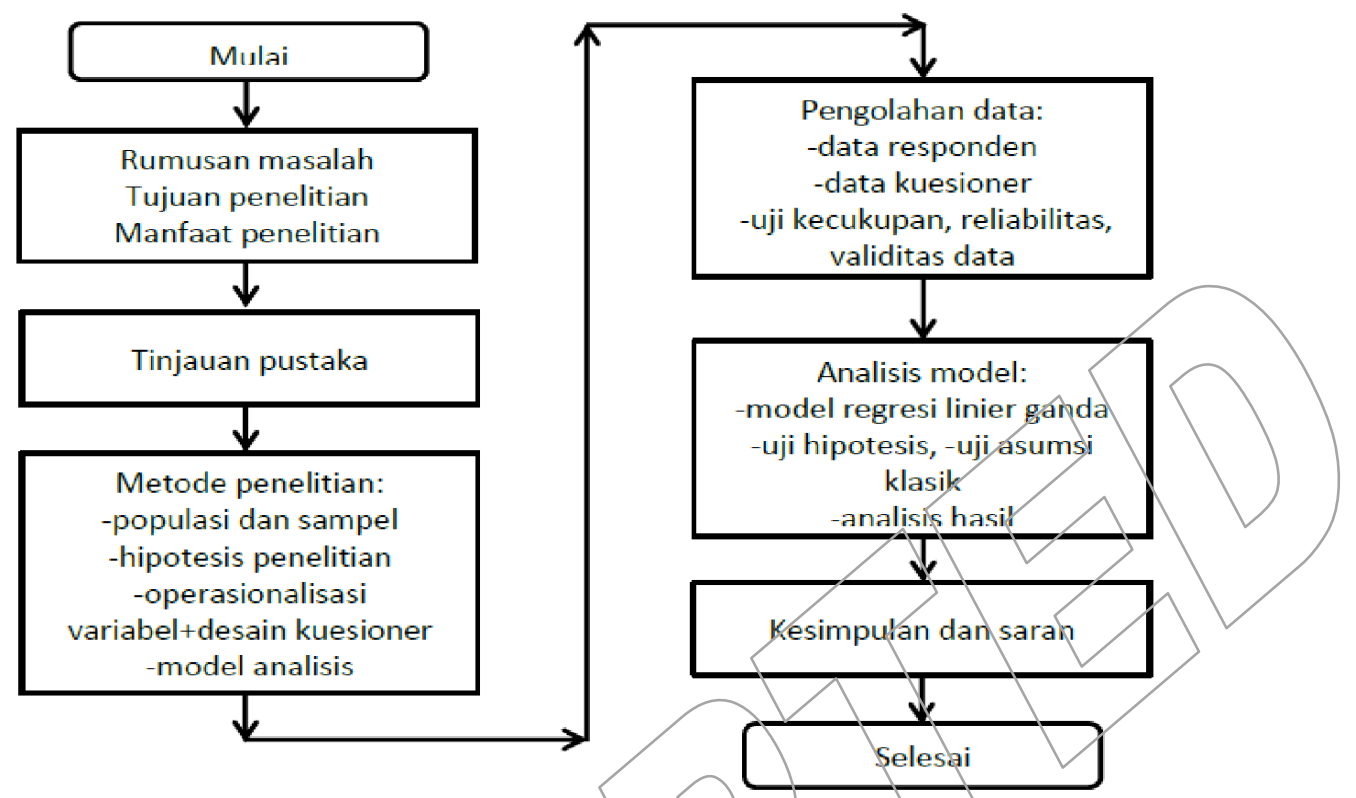

Gambar 4. Alur penelitian

\section{HASIL DAN PEMBAHASAN}

Dari sejumlah 50 sampel, semua dirisi dan dikembalikan,kemudian ditabulasi sebagai berikut:

\section{Profil Responden}

Tabel.5. Profil berdasarkan jenis kelamin dan usia

\begin{tabular}{|c|c|c|c|c|c|}
\hline No & Jenis kelamin Jumlah & frekuensi \% & Usia (tahun) & Jumlah & frekuensi $\%$ \\
\hline 1 & Laki-laki & 54,0 & $<=18$ & 12 & 24,0 \\
\hline \multirow[t]{3}{*}{2} & Perempuan & 46,0 & $18<U<=22$ & 23 & 46,0 \\
\hline & Jumlah $\bigcirc 50$ & 100 & $22<U$ & 15 & 30,0 \\
\hline & & & Jumlah & 50 & 100 \\
\hline
\end{tabular}

Tabel 6. Profil berdasarkan daerah asal dan uang saku per bulan

\begin{tabular}{llccccc}
\hline No & Daerah asal & Jumlah & $\begin{array}{c}\text { Frekuensi } \\
\%\end{array}$ & $\begin{array}{c}\text { Uang saku } \\
(\mathrm{Rp}) / \mathrm{bulan}\end{array}$ & Jumlah & $\begin{array}{c}\text { Frekuensi } \\
\%\end{array}$ \\
\hline 1 & Bandung & 21 & 42,0 & Rp. $<=500.000$ & 5 & 10,0 \\
\hline 2 & Jabar+Banten+DKI & 11 & 22,0 & $500.000<$ Rp. $<=$ & 27 & 56,0
\end{tabular}




\begin{tabular}{ccccccc}
\hline \multicolumn{7}{c}{1.000 .000} \\
\hline 3 & Jateng+Jatim+DIY & 7 & 14,0 & $\begin{array}{c}1.000 .000< \\
\text { Rp.<=1.500.000 }\end{array}$ & 8 & 16,0 \\
\hline 4 & Luar P.Jawa & 11 & 22,0 & Rp. $>1.500 .000$ & 10 & 20,0 \\
\hline & & & & & \\
\hline
\end{tabular}

Tabel 7. Profil berdasarkan pekerjaan orangtua

\begin{tabular}{clcc}
\hline No & $\begin{array}{c}\text { Pekerjaan } \\
\text { Orangtua }\end{array}$ & Jumlah & $\begin{array}{c}\text { frekuensi } \\
\%\end{array}$ \\
\hline 1 & Peg PNS/TNI/Polri & 6 & 12,0 \\
\hline 2 & Pegawai Swasta & 15 & 30,0 \\
\hline 3 & Wiraswasta/ & 17 & 34,0 \\
& Dagang & & \\
\hline 4 & Petani/Nelayan & 8 & 16,0 \\
\hline 5 & Pensiunan & 4 & 6,0 \\
\hline & & & 100 \\
\hline
\end{tabular}

Uji kecukupan, reliabilitas, validitas data Data yang telah terkumpul, kemudian dilakukan uji kecukupan data, reliabilitas instrument dan uji validitas menggunakan software SPSS, diperoleh hasil sebagai berikut:
- Uji kecukupan data, $\mathrm{n}>=\left[\left(\mathrm{z}_{\alpha / 2}\right)^{2} / \mathrm{e}^{2}\right] \cdot \mathrm{p} \cdot \mathrm{q}$ $\mathrm{n}>=\left[1,96^{2} / 0,05^{2}(100 \%(.(0 \%)]\right.$ $\rightarrow$ n mencukupi.

-Uji reliabilitas instrumen, diperoleh koefisien reliabilitas $r>7 \rightarrow$ reliabel

Tabel 8. Koefisien reliabilitas

\begin{tabular}{lll}
\hline Variabel & $\begin{array}{c}\text { Koefisien Standardized } \\
\text { Cronbach } \\
\text { Alpha }\end{array}$ \\
\hline $\begin{array}{l}\text { Bauran } \\
\text { pemasaran }\end{array}$ & $\begin{array}{c}\text { Ketera- } \\
\text { Keputusan } \\
\text { kuliah }\end{array}$
\end{tabular}

- Uji validitas data, diperoleh koefisien validitas $\mathrm{r}>\mathrm{r}$ tabe $\rightarrow$ valid

Tabel 9. Koefisien validitas

\begin{tabular}{ccccccccc}
\hline $\begin{array}{c}\text { Item } \\
\text { perta- } \\
\text { nyaan }\end{array}$ & $\begin{array}{c}\text { Nilai } \\
\mathrm{r}\end{array}$ & $\begin{array}{c}\text { Keter } \\
\text { anga } \\
\mathrm{n}\end{array}$ & $\begin{array}{c}\text { Item } \\
\text { perta- } \\
\text { nyaan }\end{array}$ & Nilai $\mathrm{r}$ & $\begin{array}{c}\text { Ketera } \\
\text { ngan }\end{array}$ & $\begin{array}{c}\text { Item } \\
\text { perta- } \\
\text { nyaan }\end{array}$ & Nilai r & Ketera \\
\hline 1 & 0,565 & valid & 9 & 0,289 & valid & 17 & 0,426 & valid \\
\hline 2 & 0,280 & valid & 10 & 0,338 & valid & 18 & 0,867 & valid \\
\hline 3 & 0,408 & valid & 11 & 0,300 & valid & 19 & 0,560 & valid \\
\hline 4 & 0,326 & valid & 12 & 0,307 & valid & 20 & 0,670 & valid \\
\hline 5 & 0,360 & valid & 13 & 0,287 & valid & 21 & 0,653 & valid \\
\hline 6 & 0,308 & valid & 14 & 0,462 & valid & 22 & 0,710 & valid \\
\hline
\end{tabular}




\begin{tabular}{llllll}
\hline 7 & 0,307 & valid & 15 & 0,275 & valid \\
\hline 8 & 0,393 & valid & 16 & 0,460 & valid
\end{tabular}

*) nilai validitas tabel $\operatorname{dg} \alpha=5 \%$ dan $n=50 \rightarrow r=0,273$

\section{Kinerja Bauran Pemasaran}

Tabel 10. Skor item pertanyaan bauran pemasaran

\begin{tabular}{clcl}
\hline $\begin{array}{c}\text { Nomor } \\
\text { item }\end{array}$ & Item pertanyaan bauran pemasaran & Skor rata2 & \multicolumn{1}{c}{ Ket } \\
\hline 1 & Kualitas program pendidikan & 3,96 & Berkualitas \\
\hline 2 & Daya tarik ketrampilan/ tambahan & 4,04 & Menarik \\
\hline 3 & Kemudahan mendapat pekerjaan & 3,98 & Mudah \\
\hline 4 & Daya tarik yayasan pemilik & 4,14 & Menarik \\
\hline 5 & Besarnya biaya kuliah & 4,32 & Terjangkau \\
\hline 6 & Kestrategisan lokasi gedung kuliah & 4,28 & Strategis \\
\hline 7 & Kualitas dosen pengajar & 4,38 & Berkualitas \\
\hline 8 & Kemudahan mengikuti proses kuliah & 4,00 & Mudah \\
\hline 9 & Kondisi fasilitas gedung kuliah & 4,22 & Baik \\
\hline 10 & Kelengkapan fasilitas laboratorium & 4,18 & Lengkap \\
\hline 11 & Variasi lokasi praktek kerja lapangan & 4,12 & Bervariasi \\
\hline 12 & Daya tarik spanduk/baliho & 3,74 & Menarik \\
\hline 13 & Kejelasan informasi di media cetak & 3,78 & Jelas \\
\hline 14 & Daya tarik iklan di media elektronik & 3,90 & Menarik \\
\hline 15 & Kelengkapan informasi dlm brosur & 4,04 & Lengkap \\
\hline 16 & Daya tarik presentasi/seminar & 4,34 & Menarik \\
\hline 17 & Daya tarik pameran/bazaar & 4,34 & Menarik \\
\hline 18 & Pengaruh referensi teman/saudara & 4,22 & Berpengaruh \\
\hline & & 4,11 & Baik \\
\hline
\end{tabular}

Skor kinerja bauran pemasaran (selain promosi), terlihat bahwa kualitas dosen dianggap berkualitas dan tertinggi skornya $(4,38)$, diikuti besarnya biaya kuliah $(4,32)$ atau biaya kuliah terjangkau, kualitas program memiliki skor terendah $(3,96)$ namun masih dianggap berkualitas. Semua variabel bauran pemasaran (selain promosi) mendapatkan skor rata-rata 4,15 atau dianggap baik/menarik.

Kinerja bauran komunikasi pemasaran (khusus promosi) Politeknik X Cimahi bervariasi, dengan skor rata-rata 4,05 atau baik/menarik.
Skor tertinggi adalah daya tarik presentasi/seminar dan pameran/bazaar $(4,34)$ atau menarik. Calon mahasiswa menganggap seminar dan pameran/bazaar ke sekolah memberikan informasi menarik yang mereka dibutuhkan. Skor terendah daya tarik spanduk/balino $(3,74)$, atau spanduk/baliho yang ada dianggap cukup menarik, namun lebih rendah dari lainnya. Total skor rata-rata untuk seluruh aspek bauran pemasaran adalah 4,11 (baik).

\section{Keputusan Kuliah}

Tabel 11.Skor item pertanyaan keputusan kuliah

\begin{tabular}{llll}
\hline No Item pertanyan keputusan kuliah & Skor rata2 & \multicolumn{1}{c}{ Ket } \\
\hline 19 & Menjadi perhatian & 4,03 & Timbul perhatian \\
\hline 20 & Menimbulkan ketertarikan & 3,98 & Tertarik \\
\hline 21 & Menimbulkan keinginan mendaftar & 4,34 & Berminat \\
\hline 22 & Kepuiusan kuliah di Politeknik X & 4,22 & Mendaftar Kuliah \\
\hline
\end{tabular}




\section{Rata-rata total 4,14 Mendaftar Kuliah}

Kinerja variabel keputusan kuliah menunjukkan bahwa, rata-rata calon mahasiswa berpendapat secara tingkatan perhatian berpendapat menimbulkan perhatian (skor 4,03), ketertarikan menyebabkan rasa tertarik dengan skor 3,98. Sedangkan jika dilihat dari tingkat keinginan (minat) untuk mendaftar, responden berminat mendaftar di Politeknik X Cimahi (skor 4,34). Sedangkan jika dilihat dari kepastian untuk kuliah/mendaftar, terlihat mereka akan mendaftar kuliah (skor 4,22).
Secara keseluruhan keputusan kuliah mencapai skor 4,14 (mendaftar kuliah).

\section{Pengaruh Bauran Pemasaran terhadap Keputusan Kuliah}

Hasil perhitungan menggunakan SPSS 20, untuk mengembangkan model regresi linier sederhana, diperoleh nilai koefisien-koefisien seperti tertera pada tabel. 13 sebagai berikut:

Tabel 12. Ringkasan koefisien regresi linier

\begin{tabular}{|c|c|c|c|}
\hline No & Koefisien/ Variabel & Nilai & Kesimpulan \\
\hline 1 & $\begin{array}{l}\text { Determinasi } \mathrm{R}^{2} \\
(\mathrm{X} \text { terhadap } \mathrm{Y})\end{array}$ & 0,614 & $\begin{array}{c}\text { Y bisa dijelaskan } 61,4 \% \\
\text { oleh } \mathrm{X}\end{array}$ \\
\hline 2 & F hitung & 6,203 & signifikan \\
\hline 3 & Selain X terhadap Y & 0,386 & $38,6 \%$ oleh faktor lain \\
\hline 4 & X terhadap Y & 0,690 & signifikan \\
\hline 5 & Konstanta & 1,248 & signifikan \\
\hline \multirow[t]{3}{*}{6} & Uji multikolinieritas & & Tidak ada multikoliniertas \\
\hline & -tolerance X & 1,000 & Tolerance $>0,1$ \\
\hline & -VIF X & 1,000 & VIF $<10$ \\
\hline \multirow[t]{4}{*}{7} & Uji otokorelasi & & Tidak ada otokorelasi \\
\hline & -koefisien Durbin-Watson & 1,732 & $(\mathrm{dU}<\mathrm{d}<4-\mathrm{dU})$ \\
\hline & $-\mathrm{dL}$ & 1,462 & $1,628<1,732<2,376$ \\
\hline & $-\mathrm{dU}$ & 1,628 & \\
\hline 8 & $\begin{array}{l}\text { Uji heteroskedastisitas } \\
\text {-pola sebaran data }\end{array}$ & $\begin{array}{l}\text { Pola titik2 } \\
\text { menyebar }\end{array}$ & $\begin{array}{c}\text { Tidak ada } \\
\text { heteroskedastisitas }\end{array}$ \\
\hline 9 & $\begin{array}{l}\text { Uji normalitas } \\
\text { (Kolmogorov-Smirnov) }\end{array}$ & normal & Normal \\
\hline
\end{tabular}


Koefisien determinasi bernilai $0,614 \quad(61,4 \%)$ yang berarti bahwa variabel Y (keputusan kuliah), dapat dijelaskan $61,4 \%$ oleh variabel $\mathrm{X}$ (bauran pemasaran). Atau bauran pemasaran mempengaruhi keputusan kuliah calon mahasiswa Politeknik X sebesar $61,4 \%$. Sedangkan 38,6\% dapat dijelaskan oleh variabel/faktor-faktor lainnya. Persamaan regresi linier sederhana yang terbentuk adalah $\mathrm{Y}=0,690 \mathrm{X}+1,248$. Hal ini berarti bahwa usaha-usaha yang dirakukan Politeknik $X$ dalam menerapkan bauran pemasaran $(7 \mathrm{P}=$ produk, price, place, process person, physical evidene, dan promosi) kepada calon mahasiswa selama ini, cukup memberikan pengaruh cukup K̂uat.

Bauran pemasaran yang dilakukan Politeknik $\mathrm{X}$ melalui berbagai kegiatan/hal (kualitas program, kemudahan mendapat pekerjaan, kualitas dosen, proses kuliah, fasilitas fisik sarana/prasarana belajar gedung laboratorium dan bentuk promosi), jika berubah sebesar 1 (satu) poin, keputusan kuliah calon mahasiswa Politeknik X akan berubah sebesar 0,690. Di sisi lain jika tidak ada (tidak dilakukan) bauran pemasaran, tetap akan ada keputusan kuliah calon mahasiswa Politeknik X Cimahi, dan memberikan pengaruh sebesar 1,248.

Sebagai perbandingan hasil penelitian Kalsum (2008), menunjukkan hasil bahwa bauran promosi dan pelayanan mampu menjelaskan $89,5 \%$ terhadap keputusan memilih kuliah mahasiswa FE Al-Azhar. Hasil kajian Muhyidin (2010) menghasilkan temuan agak berbeda sebagai berikut: tidak seluruh variabel marketing mix memiliki pengaruh yang signifikan terhadap keputusan calon mahasiswa untuk memilih perguruan tinggi swasta di Jawa Barat. Variabel yang tidak berpengaruh signifikan adalah harga (price), promosi (promotion), dan orang (people), sedangkan yang berpengaruh signifikan yaitu produk (product), lokasi (place), proses (process) dan bukti fisik (physical evidence). Penelitian Suharyanto (2011) atas calon mahasiswa Akademi Keperawatan Al-Ikhlas juga menunjukkan adanya pengaruh cukup kuat komunikasi pemasaran promosi dan nonpromosi terhadap keputusan kuliah. Studi yang dilakukan oleh Wahyuni (2012) juga menunjukkan bahwa bauran promosi cukup mempengaruhi perolehan jumlah mahasiswa baru PT-X. demikian pula hasil penelitian Darmawansyah (2014), juga menunjukkan bahwa bauran promosi (variabel Iklan, Personal Selling, Publisitas, dan Word of Mouth) secara serempak berpengaruh signifikan terhadap peningkatan jumlah mahasiswa sebesar 65,6 \%. Hasil penelitian Sukendar (2015), menurjukkan bahwa produk, harga, tempat, promosi, orang, proses dan public relation secara parsial berpengaruh signifikan terhadap keputusan keputusan pemilihan program studi D-3 Komunikasi berbasis Multimedia Politeknik Indonusa Surakarta.

\section{Usaha-usaha Perbaikan}

Usaha-usaha yang bisa dilakukan untuk dipertahankan dan memperbaiki bauran pemasaran berupa:

-aspek produk: meningkatkan kualitas program pendidikan dengan peningkatan akreditasi prodi/institusi, lahan praktek yang lebih menarik dan variatif, menambah tempat uji kompetensi untuk setiap program studi yang ada.

- harga: memperbaiki cara pembayaran dengan sistem cicilan dan proses membayar yang lebih mudah.

- tempat meningkatkan fasilitas gedung kuliah misalnya dengan $\mathrm{AC}$, dan sarana audio-visual (infokus, layar TV) yang lebih baik,peralatan laboratorium lebih lengkap dan baru.

- proses: memperbaiki proses belajar-mengajar dengan perbaikan penjadwalan kuliah, ujian, keteraturan bimbingan kerja praktek dan tugas akhir.

-person: meningkatkan kompetensi tenaga dosen dan non-dosen dengan pendidikan, pelatihan, seminar yang melibatkan lebih banyak dosen tetap/tidak tetap.

- bukti fisik: meningkatkan fasilitas fisik yang mendukung proses belajar-mengajar, fasinitas internet yang lebih cepat, fasilitas kegiatan mahasiswa (unit kegiatan mahasiswa), sarana ibadah, kantin dan lahan parkir.

-promosi (spanduk, iklan, referensi, seminar, brosur, dsb) agar dibuat lebih baik dan memiliki daya tarik, misalnya.

$\Rightarrow$ memperbaiki tampilan brosur, spanduk dengan komposisi warna dan gambar yang lebih menarik dan variatif.

$\Rightarrow$ menyelenggarakan acara yang bisa diikuti dan sesuai dengan suasana kejiwaan calon mahasiswa dengan host atau narasumber 
yang terkenal dan menarik acaranya, di kampus, di radio atau media sosial.

$\Rightarrow$ membuat brosur, pamflet, kalender atau cendera mata yang bisa digunakan dalam waktu yang lama, sehingga akan mudah diingat oleh calon mahasiswa.

\section{KESIMPULAN DAN SARAN}

\section{Kesimpulan}

1. Kinerja bauran pemasaran yang telah dilakukan Politeknik X Cimahi menunjukkan nilai rata-rata baik.

2. Keputusan kuliah calon mahasiswa rata-rata tertarik dan berminat kuliah di Politeknik X, dan jika dilihat dari kepastiannya untuk mendaftar rata-rata mereka memutuskan mendaftar.

3. Pengaruh bauran pemasaran terhadap keputusan kuliah calon mahasiswa Politeknik $\mathrm{X}$ Cimahi berpengaruh cukup kuat.

\section{Saran}

1. Variabel bauran pemasaran memberikan pengaruh yang cukup kuat. Oleh karenanya kedua variebel perlu terus dilanjutkan dan dipertahankan.

2. Besarnya pengaruh bauran pemasaran, karenanya upaya-upaya melalui kegiatan peningkatan mutu/akreditasi, peningkatan berbagai fasilitas sarana/prasarana perkuliahan, terutama kelengkapan peralatan kuliah, laboratorium, dan peningkatan mutu dosen dalam rangka peningkatan mutu perkuliahan, agar lebih diperhatikan karena lebih mempengaruhi dan menentukan keberhasilan meraih mahasiswa baru.

3. Aspek komunikasi melalui media promosi, walaupun memberikan pengaruh yang lebih kecil terhadap keputusan kuliah calon mahasiswa, namun juga jangan ditinggalkan, karena dalam jangka pendek lebih mudah dilakukan dan diperbaiki.

4. Perlunya dilakukan penelitian lebih lanjut, tentang pengaruh tampilan, desain, layout, luar maupun warna untuk media promosi spanduk/baliho, koran atau brosur yang dapat mempengaruhi terhadap keputusan kuliah calon mahasiswa. Termasuk bekerjasama dengan berbagai pihak dalam perekrutan calon mahasiswa.

\section{DAFTAR PUSTAKA}

[1]Aczel, Amir D. and Sounderpandian, J.,(2009). “Complete Business Statistics".Mc Graw Hill Int'1, 7 ed.: New York.

[2]Andreasen, A.R., Kottler, P., (2008). "Strategic Marketing for Non Profit Organization", New Jersey: Pearson Int' $1,7^{\text {the }}$.

[3]Baker, Michael J. ed. .(2003). The Marketing Book. Fifth ed. Butterworth Heinmann. Oxford GB

[4] Cooper, Donald. R., Schindler, P.S., (2008). "Business Research Methods", New York: Mc. Graw Hill Int'l, $10^{\text {th }}$ ed.

[5] Fill, Chris and Jamieson, Barbara. (2014). Marketing Communications, School Heriot-Watt University Edinburgh, United Kingdom.

[6] Darmawansyah, Surya et all. (2014). Strategi Promosi dalam Meningkatkan jumlah mahasiswa Polimedia Kreatif Makassar. Jurnal Komunikasi KAREBA Vol. 3, No. 4 Oktober-Desember 2014.Hal.256-263.

[7]Kalsum, Eka Umi, (2008). Analisis Pengaruh Strategi Bauran Pemasaran terhadap Keputusan Mahasiswa Memilih Fakultas Ekonomi Univ. Al-Azhar Medan. Tesis, Universitas Sumatera Utara.

[8] Kayode, Olujimi, (2014). "Marketing Communications". Bookboon ebook publisher.

[9] Kotler,P. (2007), Manajemen Pemasaran (Terjemhan), edisi 12, Jakarta: PT Indeks

[10] Kottler, Philip., Keller, K L., (2009). "Marketing Management", New Jersey: Pearson Educ., Int'l Edition, $13^{\text {th }}$ ed.,

[11]Kurniawan, A., (2014). "Metode Riset untuk Ekonomi dan Bisnis", Bandung.Penerbit Alfabeta.

[12] Lovelock, C. and Weird, Jochen, (2004). "Services Marketing", 5 ed,New Jersey: Pearson Int'1

[13] Muhyidin, Ujang. (2010). Pengaruh Bauran Pemasaran Jasa Pendidikan terhadap Keputusan Mahasiswa Memilih Perguruan Tinggi Swasta di Jawa Barat. Prosiding Seminar Nasional Kajian Multi Disiplin Ilmu untuk Mewujudkan Poros Maritim dalam Pembangunan Ekonomi Berbasis Kesejahteraan Rakyat. ISBN: 978-9793649-81-8.

[14]Schiffman, LG. and Kanuk, L.L., (2007). "Consumer Behavior", $9^{\text {th }}$ ed. NewJersey: Pearson Int'l. 
[15]Sugiyono, (2009). "Statistik untuk Penelitian", cetakan ke-15. Bandung: Penerbit Alfabeta.

[16] Suharyanto, (2011).Pengaruh Komunikasi Pemasaran Promosional dan Nonpromosional terhadap Proses Pengambilan Keputusan Kuliah Calon Mahasiswa Akper Al-Ikhlas Bogor, Tesis MM Unpad Bandung.

[17]Sukendar, Markus Utomo, (2015). Pengaruh Strategi Bauran Pemasaran terhadap Keputusan Pemilihan Perguruan Tinggi Program D-3 Komunikasi Berbasis Multimedia Politeknik Indonusa Surakarta. Jurnal IKON Prodi D3 Komunikasi Massa Politeknik Indonusa Surakarta Vol. 1 No. 2 Desember 2015, hal. 18-27.

[18]Undang-undang RI No. 20 tahun 2003 tentang "Sistem Pendidikan Nasional", Jakarta: Sekretariat Negara Republik Indonesia.

[19]Wahyuni, Alida. 2012. Kajian Bauran Promosi di Perguruan Tinggi X. Jurnal Liquidity Vol 1 No. 2. Jul-Des 2012. hal.175-182.

[20] Zeithaml, Valarie, A., Bitner, Marie Jo., Gremler, Dwayne D.,(2006). "Services Marketing, Integrating Customer Focus

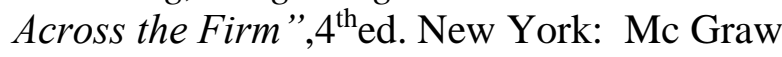
Hill Int'1 